\title{
Conceptualizing Some Verbs of Propositional Attitudes in English
}

\author{
Cherif Teimi $^{1,2}$ \\ ${ }^{1}$ Ibn Tofail University, Kenitra, Morocco \\ 2 Jazan University, Jazan, Saudi Arabia \\ Correspondence: Cherif Teimi, Ibn Tofail University, Kenitra, Morocco; Jazan University, Jazan, Saudi Arabia. \\ E-mail: teimicherif@gmail.com or cteimi@jazanu.edu.sa
}

Received: December 30, 2017 Accepted: January 17, 2018 Online Published: March 17, 2018

doi:10.5539/ijel.v8n4p64 URL: https://doi.org/10.5539/ijel.v8n4p64

\begin{abstract}
In this article, we discuss the semantics and syntax of Propositional Attitude Verbs. Our goal is to clarify and illustrate how Propositional Attitudes function and behave and put forth the conceptualization/ formalization of sentences containing this type of Verbs. We will see how intentions and beliefs are useful to study Propositional Attitudes. Also, we will argue that the semantic approach is more adequate than the syntactic one in terms of classifying Propositional Attitude Verbs. This, of course, is carried out in the framework of Conceptual Semantics that was mainly introduced by Jackendoff.
\end{abstract}

Keywords: conceptual semantics, propositional attitudes, intentions, beliefs, situations, actions, situational attitudes, actional attitudes

\section{Introduction}

Propositional Attitudes are mental states that people constitute about real world; and intentions and beliefs are said to be special cases of these ATTITUDES. In particular, intentions are important for understanding people's minds. Analyzing others' intentional actions is crucial for the analysis of social interaction. I am interested in studying propositional attitudes in the Conceptual Semantics Framework which is introduced in Jackendoff's works (e.g., Jackendoff, 1997, 2002, 2007 among others). I will see how people conceptualize situations that contain intentions and/ or beliefs. I will conduct this topic via the analysis of a class of verbs called Intentional Verbs. They are intentional in two senses. The first is that intentionality is their main property; and the second is that they select a volitional/intentional Actor. This is carried out through the analysis of Propositional Attitude Verbs in English. But, before that, we need some background about propositional attitudes, and characterization of Intentional Verbs.

\section{Situational Attitudes versus Actional Attitudes}

\subsection{Distinguishing Intentions from Beliefs}

Starting from the fact that intentions are a special case of ATTITUDE, we find it very useful to analyze Propositional Attitudes via the analysis of Intentional Verbs. With this in mind, we need to make some distinction between Propositional Attitudes, first. A primary distinction between propositional attitudes arises from the difference between beliefs and intentions. On the one hand, a belief is an attitude adopted by a person toward any situation (state or event, concrete or abstract), at any time, with any combination of characters in it. On the other hand, an intention is an attitude held by a person to perform an action in the future, immediate or far future. Moreover, an intentional action must be self-initiated; the actor must be identical to the holder of the intention. Another distinction between intentions and beliefs is that intentions, unlike beliefs, can be directed only towards future time and the action cannot be previous to the intention (See Jackendoff, 2007, pp. 147-148).

Let us see the examples in (1).

(1) a. John believes himself to have visited his uncle yesterday.

b. John claims to have visited his uncle yesterday.

c. *John intends to visit/to have visited his uncle yesterday.

As is shown in (1), a belief and claim can be directed toward the past but an intention cannot. Intentions can only be directed toward future. This future directedness or non-past directedness, as is called by Jackendoff (2007), 
occurs in all Actional Attitudes.

(2)

$$
\text { * }\left\{\begin{array}{l}
\text { John planned today } \\
\text { John decided today } \\
\text { Mary persuaded John today } \\
\text { John is willing today }
\end{array}\right\} \begin{aligned}
& \text { uncle yesterday. } \\
& \text { to visit/to have visited his }
\end{aligned}
$$

From these preliminary observations about the difference between intentions and beliefs, we can classify verbs of propositional attitudes, based on Jackendoff's (2007) work, into two major classes according to their semantic nature:

- Verbs of Situational Attitudes: as believe, claim, doubt, wish, presume, etc.

- Verbs of Actional Attitudes: like intend, plan, design, provide, decide, aim, express, prove, show and perform. Some of Propositional Attitude Verbs are ambidextrous (i.e., they express both Situational and Actional Attitudes). We will analyze some of them later.

In what follows, we will study propositional attitude verbs in English to see how they behave so that we can understand how speakers of English do conceptualize propositional attitudes. Let us consider the examples in (3).

(3) a. John believed that he was shorter than Bob.

b. John believed that he was born ten years earlier than he really was.

c. John believed that Susan was descended from royalty.

d. John intended to break the pen.

e. John intended drop the goalkeeper.

f. John intended to embarrass Mary.

From the examples in (1), (2) and (3), we can detect the difference between intentions and beliefs. We notice, from the first glance, that there is a semantic difference between intentions and beliefs. In (3a) John has a mental state toward himself on the one hand, and towards Bob on the other hand. He believes that he is shorter than Bob and Bob is taller than him. Also, in (3b) John has a belief toward the event of his birth. He believes that he was born ten years earlier than what was told to him or what the official documents declare. In (3c) John has a mental attitude toward Susan since he believes that she descended from Royalty. Hence, from this simple description, a belief is a mental attitude formed by a person toward an event or a state. Sentences expressing this kind of events and states are said to express Situations or Situational Attitudes, and verbs used in such sentences are called Situational Attitude Verbs.

Concerning intentions, we notice from the examples in (3d, e, f) that intend in English expresses actions. In ( $3 \mathrm{~d}$ $\&$ e), there are actions performed intentionally by John. In (3f), we are in front an abstract action performed by John (perhaps by talking to Mary in front of other people). Here, there is a causative action. John caused Mary to be embarrassed. The conceptual structure of this sentence contains the function CAUSE. We will discuss Conceptual Structures in detail in this article later on. Hence, intention is a mental attitude adopted by a person in order to perform a particular action. In this light, and following Jackendoff (2007), we put forth the conceptual structures of the verbs believe (4a) and intend (4b). COM stands for "commitment". X is committed to BELIVE that $\mathrm{P}$ or to INTEND to $\mathrm{P}$.

(4) a. X believes that $P$.

[X COM [Situation, - Action P]]

b. $\mathrm{X}$ intends to $\mathrm{P}$.

$\left[\mathrm{X}^{\alpha} \mathrm{COM}\left[\right.\right.$ Situation, + Action $\alpha \mathrm{ACT} ;\left[\right.$ Time $\left.\left.\left.\mathrm{T}_{2} \geq \beta\right]\right] ; \mathrm{T}_{1}{ }^{\beta}\right]$

Looking deeply at the conceptual structure of believe and intend, we can infer that they express the very same attitude differing only in that the first is directed at a non-Action and the latter at an Action. The two verbs share 
the function COM. To believe that a situation is such and such is to be committed to its existence and to intend to perform an action is to be committed to performing it. This is from a semantic point of view. Let's now see the issue from a syntactic point of view.

In English, Situational Attitude Verbs occur with an indicative that-clause as in (3a, b, c), whereas Actional Attitude Verbs occur with an infinitival clause as seen in (3d, e, f).

Unfortunately, neither Situational Attitude Verbs nor Actional Attitude Verbs can be distinguished by their syntax. It is true that Situational Attitude Verbs in English occur with that-clauses and Actional Attitude Verbs go with the infinitival clauses typically, but this is not the case for all verbs of propositional Attitudes. Wish and claim, for instance, express situational attitudes though they occur with infinitival phrases (Jackendoff, 2007, p. 250).

$$
\begin{aligned}
& \text { John wished claimed ... } \\
& \qquad \begin{array}{l}
\text { To be shorter than Bob. } \\
\text { To have been born ten years earlier. } \\
\text { To be descended from royalty. }
\end{array}
\end{aligned}
$$

(Note 1)

Therefore, we cannot depend on syntax to distinguish verbs of Situational Attitudes from those of Actional Attitudes. The suitable approach, adopting Jackendoff's point of view, is to admit that all verbs of propositional Attitudes can express the same attitude in either case and the difference lies only in whether the attitude is taken toward a situation or an action (Jackendoff, 2007, p. 253).

As a matter of fact, distinguishing verbs of propositional attitudes into Situational Attitude Verbs and Actional Attitude Verbs by their syntax is impossible. The semantic division of these verbs, however, is more accurate. Verbs such as believe, claim, doubt, wish... etc. are Situational Attitude Verbs and verbs such as intend, decide, aim, express, focus, design ... etc. are Actional Attitude Verbs. Now, we deal with ambidextrous propositional attitude verbs which can express both Situational and Actional Attitudes.

\subsection{The verb Convince}

Consider the examples in (6).

(6) ACTIONS:

a. John convinced Bill to visit his uncle.

b. John convinced Mary to come to the party.

c. John convinced Susan to buy a cat.

\section{SITUATIONS:}

d. John convinced Bill that it was raining.

e. John convinced Bill that the theorem is provable.

f. John convinced Bill that Sara will bring a cake to the party.

Here in (6) the verb convince expresses both Situational and Actional Attitudes. From a syntactic perspective, it seems that when the verb convince is followed by the to-infinitive, it expresses Actions as in (6a, b, c). Otherwise, it expresses Situations when directly followed by the complementizer that as in $(6 \mathrm{~d}, \mathrm{e}, \mathrm{f})$. However, the Conceptual Structure of the sentences in (6) contains the function CAUSE. The Conceptual Structure of the sentences $(6 \mathrm{a}, \mathrm{b}, \mathrm{c})$ will roughly be:Y INTEND to CAUSE X BE CONVINCED to P. The consequences here are ACTIONS. The Conceptual Structure of the sentences in $(6, \mathrm{~d}, \mathrm{e}, \mathrm{f})$ will roughly be: Y INTEND to CAUSE X BE CONVINCED that $\mathrm{P}$ is such and such. The consequences are SITUATIONS. Therefore, to figure out if a sentence with the verb convince expresses an Action, we have to see if it passes the following test: Y INTEND to CAUSE $\mathrm{X}$ to $\mathrm{P}$, and to figure out if a sentence expresses a Situation, we should see if it passes the test: $\mathrm{Y}$ INTEND to CAUSE X BELIEVE that P. Hence, convince is the causative of believe and intend. It can either mean "cause to come to believe" or "cause to come to intend". Thus, convince can be formalized as follows (7).

(7) $\mathrm{Y}$ convinces $\mathrm{X}$ that $\mathrm{P} /$ to $\mathrm{P}$.

[Situation, + Eventive Y CAUSE [INCH [X COM [Situation P]]]] 
Therefore, in cases of actions as in $(6 \mathrm{a}, \mathrm{b}, \mathrm{c})$, the $\mathrm{P}$ will take the restirction [+Action] as formalized in $(8 \mathrm{a})$, and in cases of situations as in (6d, e, f), the $P$ takes the restriction [-Action] as formalized in (8b).

(8) a. $\mathrm{Y}$ convinces $\mathrm{X}$ to $\mathrm{P}$.

[situation, +Eventive Y CAUSE [INCH [X COM

$$
\left.[\text { Situation, +Action } \alpha \text { ACT; [Time T2 } \geq \beta]] ; \mathrm{T}_{1}^{\beta}\right] \text { ]] }
$$

b. $\mathrm{Y}$ convivces $\mathrm{X}$ that $\mathrm{P}$.

[situation, +Eventive Y CAUSE [INCH [X COM

$$
\text { [Situation, -Action } \left.\left.\left.\alpha \text { ACT; [Time T2 } \geq \beta]] ; \mathrm{T}_{1}^{\beta}\right]\right]\right]
$$

\subsection{The Verb Agree}

The verb agree in English denotes both Situational and Actional Attitudes' meanings. The verb denotes 'presumption' or 'acceptance' in cases of Situational Attitudes (i.e. to presume that something is such and such), whereas it denotes 'acceptance' or 'decision' in cases of Actional Attitudes (i.e. to accept or decide to do such and such). Consider (9).

(9) a. John agreed that it was raining yesterday.

b. John agreed that he was $\beta o \rho v 10$ years before Bill.

c. John agreed to visit his $v \vee \chi \lambda \varepsilon$ tomorrow.

In $(9 \mathrm{a}, \mathrm{b})$ we are in front of Situations where John presumes/ accepts that it was raining and that he was born 10 years before Bill. Therefore, the meaning of agree in these two examples is to presume. The sentence (9c) expresses an Actional Attitude. John has an intention to perform an Action of visiting his uncle. Besides, looking deeply inside the structure of the sentence (9c), we find out that there is a CAUSE function; another person CAUSED John to accept to go to visit his uncle. Thus, the outcome is that John came to INTEND to visit his uncle tomorrow. Thus, the conceptual Structure of $(9 \mathrm{c})$ will roughly be: Y CAUSED X to come to INTEND to do such and such. The conceptual structure of sentences in (9) will be:

(10) a. Actions: X Agrees to P.

[situation, +Eventive Y CAUSE [INCH [X COM

$$
\left.\left.\left.\left[\text { Situation, }+ \text { Action } \alpha \text { ACT; }\left[\text { Time }^{T} 2 \geq \beta\right]\right] ; T_{1}^{\beta}\right]\right]\right]
$$

b. Situations: X Agrees that $\mathrm{P}$.

[Situation, +Eventive Y CAUSE [INCH [X COM

$$
\text { [Situation, -Action } \left.\alpha \text { ACT; [Time T2 } \geq \beta] \text { ]; } \mathrm{T}_{1}^{\beta}{ }^{\beta}\right] \text { ] }
$$

\subsection{The Verb Decide}

Consider the examples in (11).

(11) a. John decided $\tau \eta \alpha \tau$ Mary descended from Descartes'.

b. John decided to $\varpi \iota \iota \imath \tau$ his uncle tomorrow.

The verb decide in English expresses both Situational and Actional Attitudes as is clear from the examples in $(11 \mathrm{a}, \mathrm{b})$. The meaning of decide in (11a) is 'come to believe'; John came to believe that Mary descended from Descartes'. (11b) expresses an Actional Attitude. John has the intention to visit his uncle tomorrow. The conceptual structures of decide in English will be (12a) and (12b) for Situations and Actions respectively:

(12) b. X decides that $P$.

$[\mathrm{X}$ COM [situation, -Action P]]

c. $\mathrm{X}$ decides to $\mathrm{P}$.

[Situation, +Eventive INCH [X COM]

$$
\left.\left.\left.[\text { Situation, }+ \text { Action } \alpha \text { ACT; }[\text { Time } \mathrm{T} 2 \geq \beta]] ; \mathrm{T}_{1}^{\beta}\right]\right]\right]
$$

\subsection{The Verb Swear}

Another ambidextrous Propositional Attitude verb that behaves as the above analyzed verbs of is the verb "swear" in English. Take the following examples. 
(13) a. John swore that Mary was descended from Royal family.

b. John swore to join Oxford University next year.

swear in English expresses Situational and Actional Attitudes. The sentence in (13a) expresses Situational Attitudes. John in (13a) does not perform an action but expresses his Attitude toward a Situation. By contrast, the sentence in (13b) expresses Actional Attitudes. John has an Actional Attitude toward joining Oxford University next year. Therefore, as we have seen in (13), the verb "swear" in English express both Situational and Actional Attitudes. The formalization of the verb "swear" will be similar to Propositional Attitude verbs:

(14) a. X swears that $P$.

[Situation, +Eventive [X COM [Situation, -Action P]

b. X swears to $\mathrm{P}$.

[Situation, +Eventive INCH [X COM

$$
\text { [Situation, +Action } \left.\left.\left.\alpha \text { ACT; [Time T2 } \geq \beta]] ; \mathrm{T}_{1}^{\beta}\right]\right]\right]
$$

To sum up, we notice from the conceptualization of the analyzed verbs above that Propositional Attitude Verbs in English fall into two formalizations. Either they go under the formalization of the situational attitude verbs (X BELIEVE that P) or of the Actional ones (X INTEND to P). In other words, Propositional Attitude Verbs are either situational or actional; and believe and intend are the prototypes of the two classes respectively. And each of the classes contains a set of verbs that share similar semantic properties which group them together.

\section{Conceptualizing Propositional Attitudes}

Conceptualizing propositional attitudes necessitates some formal differences between situations and actions since there is a semantic distinction between the two. According to Jackendoff (2007 p: 255) "on one hand, actions are a special subclass of situations but on the other hand, actional attitudes can be differentiated from situational attitudes."

Generally speaking, in conceptual semantics, things (including events and states) are distinguished in terms of their ontological categories, and each category contains a set of things that share some characteristics and properties. For that reason, and to distinguish actions from situations, Jackendoff introduces another ontological category; Action, distinct from Situation. However, since actions are a subset of situations, the difference between the two can be attributed to just a difference in the value of one or more features. For example, Events and States are both kinds of Situations which can be categorized as situations that are [+Eventive] and [Eventive] respectively (ibid). Consider the following examples.

(15) a. John is tall.

b. John was hit by a falling brick.

Both (15a, b) are situations, but (15a) is [-Eventive], therefore it is a state, and (15b) is [+Eventive], therefore, it is an Event. In this context, actions are also distinguished from events. Yet, actions are a subclass of Events. Events are said to be divided into two classes. One class represents pure Events, something happening, and the other represents Actions, something an Actor is doing (ibid p: 256). As a result, pure events are seen as [-Action] and Actions are [+ Action]. The formalization taken from Jackendoff (2007) illustrates what we have stated here.

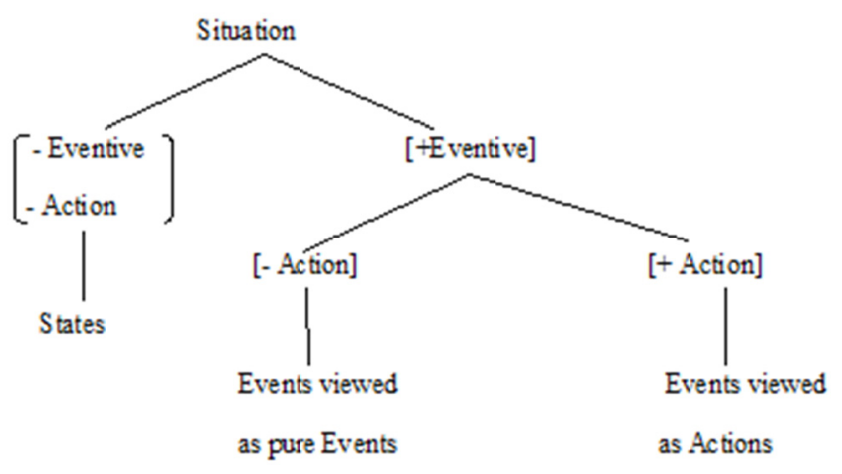


According to this taxonomy, verbs of situational attitudes such as believe, claim and wish apply to a [Situation, Action] constituent, and verbs of actional attitudes such as intend, plan, design, aim, express etc. apply to a [Situation, + Action] constituent.

Another way to distinguish pure events from actions is to see whether the sentence in question passes the test "what X did" or the test "what happened was". Examples in (17) illustrate this point.
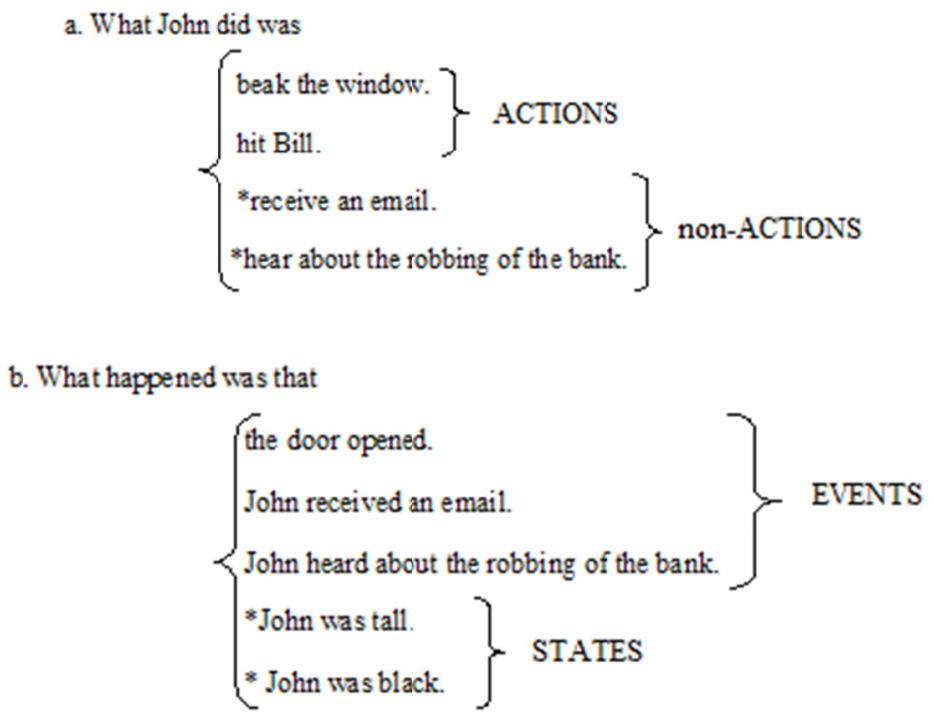

Events can also be [+ACTION ]if they involve the role ACTOR, the element that performs the action. Thus, an action is an event corresponding to the role [ACTOR] (Jackendoff, 1983, p. 180). Moreover, concerning ambidextrous verbs such as convince and decide in English, they can be used in any type of [Situation]. If the situation in question is [- Action], they will function as verbs of situational attitudes, whereas they will function as verbs of Actional attitudes if the situation is [+Action] (recall the examples in (6)).

\subsection{The Conceptual Structure of intend in English}

Now, we shall assign Conceptual Structures to Propositional Attitude Verbs based on the works of Jackendoff (e.g., 1983, pp. 160-187; 1987, pp. 369-411 and 2007, pp. 255-272) and van der Zee \& Urpo (2000).

(18) John intended to break the window.

The Conceptual Structure of (18) is as follows:

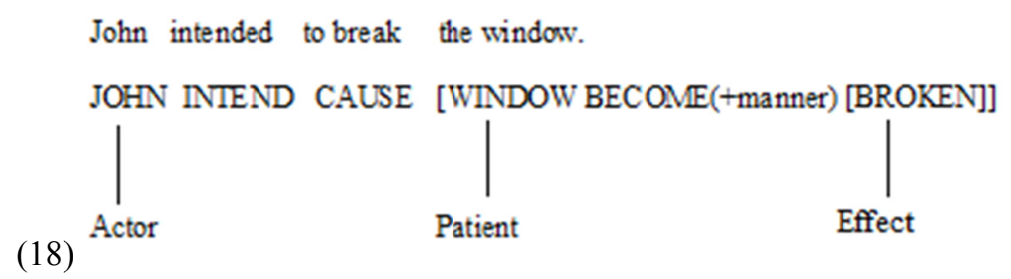

Roughly speaking, (18) describes an Actor bringing about the action of breaking the window. Here, we are in front of Events that are [+Action] since the Actor intended to bring about the event. According to the formalization in (16), this event is [+Action], thus, it is an Action and not a pure event. Another way to prove whether sentence expresses a pure event or action is to use the Actor test: what X did was... (see e.g., Jackendoff (2007, p. 198)). Applying this test to (18) proves that we are in front of an action: What John did was break the window. Now, looking deeply into the Conceptual Structure of (18), we figure out that there are two functions; INTEND and CAUSE. On one hand, the function INTEND holds John's attitude to bring about the action and on the other hand, the function CAUSE holds the action brought about, the breaking of the window. Furthermore, from the action expressed in (18), we find out that intentional actions are purposive since they have consequences or effects; the intended action is meant to bring about an effect; the purpose behind performing a 
particular action. As pointed out by Gillett and McMillan (2001, p. 103) "Actions are behaviors that are, in some sense, brought about by people as a result of purposive mental acts."

Another point worth discussion here is the role Actor in the conceptual structure of a sentence with intentional verbs. What are the restriction(s) on the role Actor that must be respected when forming a sentence with an intentional verb? The actor performing an action in these contexts must bear some properties. First, the Actor must be [+Animate]. The propositional attitude verbs or intentional verbs are said to select the Actor that is animate, and preferably but not necessarily, a person from a social environment; a human being (Note 3). However, it seems, as stated by Jackendoff $(1987$, p. 396) "that any Actor, if animate, is subject to [this] ambiguity, unless the verb specifically selects for a volitional Agent, as do, for instance, buy and look." Here I am interested in the clause "unless the verb specifically selects for a volitional Agent". All intentional verbs select for a volitional Agent/Actor. The Actor must be able to act intentionally and the Action must be intentional. Second, the Actor is preferably [+ Human]. Take the following examples.

(19) a. The man killed the boy.

b. The man intended to kill the boy.

c. The dog bit the boy.

d.? The dog intended to bite the boy.

e.?? The dog intended to kill the boy by biting him several times.

Sentence (19a) is ambiguous (Note 4). We cannot assert that the man intentionally killed the boy. The same thing can be said about the sentence in (19c). In (19b), the verb intend takes off this ambiguity. The man intentionally killed the boy. However, using the intentional verb intend with a non-human Actor, though animate, gives us odd sentences as in (19d, e) (Note 5). This suggests two things. (a) intentional verbs are intentional per se. To put it differently, intentional verbs are what determine the intentionality of the action in question. (b) intentional verbs select the Actor that is able to act intentionally. However, the oddity of $(19 \mathrm{~d}$, e) results from the fact that dogs cannot intend to bring about the consequences as is the case with human beings. But, if we replace the dog with a chimp, which is said to be able to think and act intelligently, this oddity will be reduced or definitely eliminated. In all cases, the only restriction that must be fulfilled here is that the Actor must be able to act intentionally and volitionally. With this in mind, for a sentence to express an intentional action, the Actor must be $[+$ animate, + volitional]. Here, the feature [+ volitional ] solves the problem; it does not matter if the Actor is human or animal. All that matters is that this Actor must be able to act intentionally/volitionally. Taking the role Actor this way, we can represent the action tiers of (19a-c) as (20a-c) respectively (Note 6).

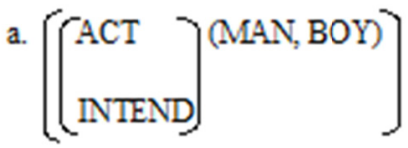

\section{or $[\mathrm{ACT}(\mathrm{MAN}, \mathrm{BOY})]$}

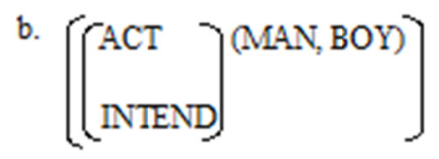

\section{c. $[\mathrm{ACT}(\mathrm{DOG}, \mathrm{BOY})]$}

The conceptual structures in (20a-c) represent intentions or lack thereof of the sentences in (19a-c). However, the structures in (20a-c) represent only the intentionality or lack thereof of the Actor performing the action. What is missed is the representation of the consequences of the action brought about. The representation in (18) remains more sufficient.

Another point worth mentioning here is the insertion of the function INTEND. As a matter of fact, adding this function to the conceptual structure of Propositional Attitude Verbs has an empirical reason. The function CAUSE alone does not make a distinction between intentional actions and non-intentional ones. Look at the following examples. 
(21) a. The wind rolled the ball into the room.

b. John rolled the ball into the room.

c. John intended to roll the ball into the room.

Here, the sentence (21a) contains a non-animate and non-volitional actor, the wind, which cannot act intentionally. Yet, it can cause an action or perform an action. In (21b) we have a sentence with an animate and volitional actor but we cannot infer that the action was performed intentionally or contrariwise. (21c) is apparently intentional. Therefore, (21a-c) can be represented as (22a-c).

(22) a. The wind rolled the ball into the room.

[Event CAUSE ([Thing WIND], [Event GO ([Thing BALL], [Path INTO ROOM])])]

b. John rolled the ball into the room.

[Event CAUSE ([Thing JOHN], [Event GO ([Thing BALL], [Path INTO ROOM])])]or,

[EVENT INTEND [CAUSE ([Thing JOHN], [Event GO ([Thing BALL], [Path INTO ROOM])])])]

c. John intended to roll the ball into the room.

[Event INTEND [CAUSE ([Thing JOHN], [Event GO ([Thing BALL], [Path INTO ROOM])])])]

The conceptual structure in (22a) contains the function CAUSE that holds the two arguments; the Actor, wind, and Theme, ball, the argument over which the action is performed. Here, though the role Actor is non-animate and non-volitional, it can cause an event to happen. Compare this to the conceptual structures in (22b) and (22c). In (22b), I put two representations since the sentence in (21b) is ambiguous. The first indicates that the action is non-intentional, and the second indicates that the action is an intentional action. However, although Jackendoff (e.g., Jackendoff, 1983, pp. 174-187) talks about willful actions, he does not represent for this will/volition. But, he later on adjusted the formalization of conceptual structures of willful actions and added the function VOL to represent volitional/intentional actions (see Jackendoff, 1987, pp. 396-397). Based on this and for empirical reasons, we put forth the representation of $(21 \mathrm{c})$ as $(22 \mathrm{c})$. The presence of the function INTEND is necessary for making a distinction between intentional and non-intentional actions.

\section{Conclusion}

In this article, we saw how intentions and beliefs are very helpful to study propositional attitudes since they are special case of ATTITUDE. However, there are noticeable differences between the two mental states. The most important difference is that intentions are necessary directed toward future. By contrast, beliefs are directed toward all times. Further, beliefs are likely associated with Situations whereas intentions are to be associated with actions. In this respect, distinguishing beliefs from intentions is not on a syntactic but on semantic basis. The semantic division of propositional attitude verbs into Actional Attitude verbs and Situational Attitude verbs is more accurate than the syntactic one.

Furthermore, the holder of the intention to perform an action or bring about an event must bear some properties. The necessary property is that it must be animate, [ + animate]. The intentional verbs select animate Actors, and preferably, but not necessary, human Actors, [+human]. However, any Actor, even human, is subject to ambiguity. That is, not any action performed by an intentional actor is necessary intentional. The action is judged to be fully intentional if and only if the Actor intends to perform it and bring about a specific consequence. Otherwise, the action would not be intentional, or at least, not fully intentional.

\section{Acknowledgement}

Thanks are due to my supervisor Dr. Boujemaa Boudali and co-supervisor Dr. Mohamed Ghalim.

\section{References}

Bratman, M. E. (1987). Intentions, plans, and practical reason. Cambridge, Mass. Harvard University Press.

Chomsky, N. (1995). The Minimalist Program. Current studies in linguistics. Cambridge, MA.: MIT Press. Retrieved from http://libgen.org/; http://gen.lib.rus.ec/

Chomsky, N. (2002). On Nature of Language. Cambridge: Cambridge University Press. https://doi.org/10.1017/CBO9780511613876

Culicover, P., \& Jackendoff, R. (2005). Simpler Syntax. New York: Oxford University Press Inc. https://doi.org/10.1093/acprof:oso/9780199271092.001.0001

Gillet, G. R., \& Mc Millan, J. (2001). Consciousness and Intentionality. Amsterdam: John Benjamins Publishing 
Company. https://doi.org/10.1075/aicr.27

Jackendoff, R. (1983). Semantics and Cognition. Cambridge: MIT Press.

Jackendoff, R. (1987). The Status of Thematic Relations in Linguistic Theory. Linguistic Inquiry, 18(3), 369-411. Retrieved from https://fr.scribd.com/document/208168694/jackendoff03

Jackendoff, R. (1997). The Architecture of Language Faculty. Cambridge, MA.: The MIT Press Cambridge. Retrieved from http://libgen.org/; http://gen.lib.rus.ec/

Jackendoff, R. (2002). Foundations of Language: Brain, Meaning, Grammar, Evolution. New York: Oxford University Press Inc. https://doi.org/10.1093/acprof:oso/9780198270126.001.0001

Jackendoff, R. (2007). Language, Consciousness, Culture. Cambridge: The MIT Press Cambridge. Retrieved from http://libgen.org/; http://gen.lib.rus.ec/

van der Zee, E., \& Nikkane, U. (2000). Cognitive Interfaces: Constraints on Linking Cognitive Information. New York: Oxford University Press. Retrieved from http://libgen.org/; http://gen.lib.rus.ec/

\section{Notes}

Note 1. The examples in (5) are from Jackendoff (2007 p. 250).

Note 2. The sentence in (11d) is from Jackendoff (2007, p. 252).

Note 3. Adding the restriction [+Human] on the role Actor may put us at risk! If we do so, we must experimentally prove that Animals cannot act intentionally. However, we don't need to pursue this discussion since intentional verbs select only the Actors that are capable of acting volitionally/intentionally.

Note 4. All non-intentional verbs are subject to such ambiguity. Non-intentional verbs can also be called ambiguous verbs. They are ambiguous in the sense that they can be used to express both intentional and non-intentional actions.

Note 5. In note 4, we asserted that adding the restriction [+Human] on the role Actor is risky. Now, though it seems that sentences with non-human Actors are odd, we cannot give a final judgment that the role Actor must be [+Human] when used with intentional verbs. All we need is to be sure that the Actor is capable of acting intentionally (whether it is a human being or an animal.)

Note 6. I replace the function VOL (volition) put by Jackendoff (1987) with INTEND since we study intentions and not volitions. Yet, Intention and Volition are used interchangeably.

\section{Copyrights}

Copyright for this article is retained by the author(s), with first publication rights granted to the journal.

This is an open-access article distributed under the terms and conditions of the Creative Commons Attribution license (http://creativecommons.org/licenses/by/4.0/). 